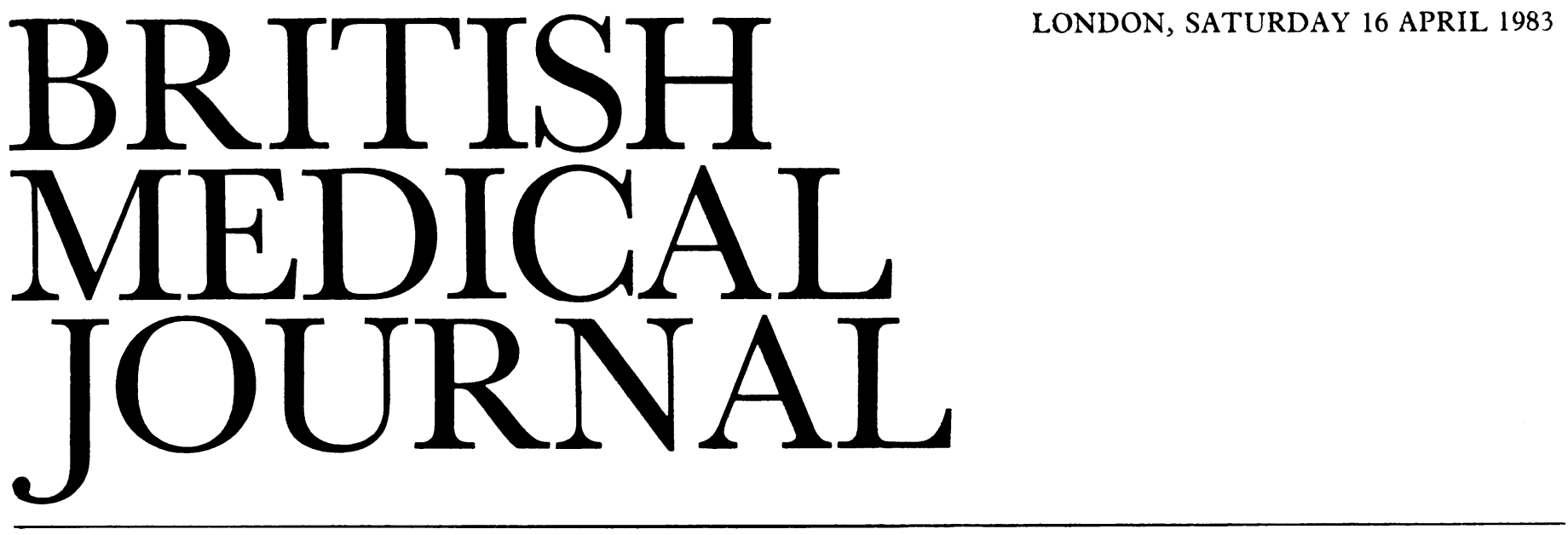

\title{
Can't audit? Won't audit!
}

By coincidence several articles appeared in the weekly press of 8 January 1983 that pointed to the need for clinical audit. The $B M F$ reported that in an area of general practice only one third of men had had their blood pressure recorded, though there was no information on the percentage of general practitioners who failed to carry out this simple procedure. ${ }^{1}$ A survey of the prescriptions for antibiotics in a city hospital claimed to show evidence of both unnecessary $\left(35^{\circ}{ }_{0}\right)$ and inappropriate $(16 \%)$ prescribing and that an educational programme had had no beneficial effect; it concluded that "much might be achieved by audit if this desire for improvement emanated from the clinicians themselves." 2 In the Lancet a review sponsored by the King Edward's Hospital Fund for London on the American system of hospital accreditation ${ }^{3}$ concluded, "There is a place for the independent voluntary assessment of quality in our own health services," and also, "the method of interdisciplinary peer review can work well." Following its pioneer survey, ${ }^{4}$ the Nuffield Provincial Hospitals Trust published an important collection of essays derived from a meeting where a group of doctors described what was or might be done if audit were undertaken in a number of specialties, particularly if the royal colleges directed such audits. ${ }^{5}$ The trust has also recently issued a well publicised book on anaesthetic deaths. ${ }^{6}$

The main functions of audit are monitoring and upgrading standards of health care. The concept may be broadened to include identifying doctors who have a poor performance and monitoring their improvement. But most doctors in Britain are reluctant to admit, in public, that a small number of their colleagues might be offering a low standard of care, due to ill health, ignorance, or idleness-which is completely different from making the occasional mistake or having an off day, usually due to overwork. They are equally reluctant to look into the methods (such as peer review) by which the profession may identify and monitor those who have a persistently substandard performance. We are led to believe that in the United States doctors are more willing to cooperate in peer review and similar such procedures, whether as assessors or assessed. Certainly the (American) Joint Commission on Accreditation of Hospitals publishes a quarterly Quality Review Bulletin which documents the results of audit and peer review procedures.
Why, then, is there a widespread reluctance in Britain to accept medical audit? Doctors may not believe that clinical audit, including peer review, really works and that it can be of benefit to the profession. They may not accept that audit can identify doctors who are in most need of guidance and helpthough they may forget it is these doctors' patients who are truly in need of help. Some doctors are reluctant to take part in any procedures that seem to be judging their colleagues-this is, perhaps, what the public believes. But doctors certainly do not fail to recognise that they have colleagues who are persistently poor performers. They may believe, however, that if poor performers are identified this will destroy the general confidence and trust that patients have in their doctors, making the exe rcise self defeating. There is a genuine concern that even if such poor performers were identified there is no way of remedying matters under the current British system of postgraduate education, specialist accreditation, and National Health Service contracts. If this is so the exercise will have been a waste of effort.

Can these questions be answered? Take the example of $\mathrm{Dr}$ A, a general practitioner who is 20 years out of date and too old and ill to carry on; or Dr B, a consultant who does only five of his nine sessions, and perhaps this is just as well for his clinical skills have greatly deteriorated and no effort has been made to revive them. Deficiencies in medical practice of these kinds are seen, and hiding such deficiencies only prevents appropriate action being taken. Patients' trust in their doctors might be increased by the knowledge that the profession is putting its own house in order. There are methods of checking and comparing clinical knowledge and practice, many of which are referred to above. ${ }^{3-5}$ If these methods applied to everyone and to all specialties, not just to those who offered to take part, objections might be less. Many of us now inspect each other's departments for college accreditations, and this is done with no loss of good will.

Consultant contracts virtually guarantee security of tenure, and without a two tier consultant structure promotion is no stimulus to maintain clinical standards as it is for academic medical staff. (One hopes that distinction awards are not relevant. ${ }^{7}$ ) Thus it is difficult to know what should be done to maintain or improve standards of clinical practice. Clinicians 
might learn from the pathologists, who with the encouragement of their royal college, have introduced quality control schemes and can offer confidential advice to individual users. ${ }^{8}$ Though these schemes are voluntary and only test limited aspects of pathologists' work they have been almost universally taken up, and standards have improved. There are now excellent confidential self assessment schemes available based on those used in the United States, though in Britain experience in their use is, as yet, limited.

Other royal colleges, it is up to you-if suitable voluntary schemes are not widely taken up, or if they do not prove to be effective, further efforts will have to be made.

Professor of Chemical Pathology,

Royal Free Hospital and School of Medicine,

London NW3 2 QG

1 Ritchie LD, Currie AM. Blood pressure recording by general practitioners in north-east Scotland. Br Med f 1983;286:107-9.

2 Swindell PJ, Reeves DS, Bullock DW, Davies AJ, Spence CE. Audits of antibiotic prescribing in a Bristol hospital. Br Med f 1983;286:118-22.

${ }^{3}$ Maxwell R, Day $M$, Hardie $R$, Lawrence $H$, Rendall $M$, Walton $N$. Seeking quality. Lancet $1983 ; \mathrm{i}: 45-8$.

- McLachlan G, ed. A question of quality? Roads to assurance in medical care. London: The Nuffield Provincial Hospitals Trust, 1976.

5 McLachlan G, ed. Reviewing practice in medical care. Steps to quality assurance. London: The Nuffield Provincial Hospitals Trust, 1981.

- Lunn JN, Mushin WW. Mortality associated with anaesthesia. London: The Nuffield Provincial Hospitals Trust, 1982.

$?$ Anonymous. Negative distinction awards. Lancet 1981 ;i:715.

Whitehead TP, Woodford FP. External quality assessment of clinical laboratories in the United Kingdom. F Clin Pathol 1981 ;34:947-57.

\section{Benefits of self monitoring of blood glucose}

The concept of self monitoring in diabetes is not new. In 1797 John Rollo reported the measurement of urinary volume by a patient to help monitor treatment and commented ${ }^{1}$ on the, "influence of even a slight variation from a proper diet and confinement in reproducing the disease." Estimation of the glucose content of the urine by boiling it with Fehling's solution has given way to other more convenient semiquantitative methods using tablets or dipsticks. These results may be misleading, ${ }^{2}{ }^{3}$ however, and are of no discriminatory value in the normal or hypoglycaemic range. Furthermore, many patients find urine testing unpleasant.

In the late 1970s insulin dependent diabetic patients began using reflectance meters and glucose oxidase impregnated strips to measure capillary blood glucose. ${ }^{4}$ The concept of patients using tests of their own blood glucose concentrations to optimise their treatment was attractive, especially as more emphasis was being given to the association between diabetic complications and control. ${ }^{6} \mathrm{~A}$ range of portable battery operated devices is now available as well as strips for direct visual reading, and with care patients can obtain sufficiently accurate results for decisions about management. ${ }^{7-10}$

Just how much self monitoring of blood glucose has affected the control of patients' diabetes is controversial. Many physicians can point to individual cases where the introduction of monitoring has revolutionised control, ${ }^{11}$ and sustained improvement has been maintained in selected groups. ${ }^{12}$ But in the absence of controlled studies with self monitoring as an independent variable possible explanations for these results include the effects of increased attention and motivation by enthusiastic physicians. In pregnant diabetics, generally a well motivated group, equally good results have been obtained with or without the use of self monitoring of blood glucose. ${ }^{13}$ Worth and his colleagues in Newcastle upon Tyne recently $\stackrel{8}{2}$ failed to show any advantage, in terms of glycaemic control, of testing blood rather than urine in intensively educated patients randomly assigned to each method. ${ }^{14}$ In this and 7 other studies ${ }^{15} 16$ some initial improvement was followed by deterioration, perhaps owing to waning enthusiasm on the part of the patients.

Managing diabetics is not, however, concerned only with $\overrightarrow{\overrightarrow{0}}$ improving long term indicators of control such as glycosylated 0 haemoglobin concentrations, desirable though that may be. Patients' preferences should be taken into account; thus $\frac{\vec{m}}{\overrightarrow{7}}$ Newcastle patients preferred testing blood to urine. Little $\stackrel{\mathbb{D}}{\stackrel{\circ}{ }}$

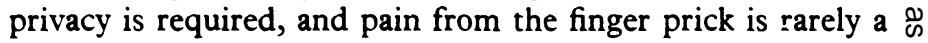
problem. ${ }^{4}$ Patients may feel their control is better without $\overrightarrow{0}$ any improvement being recorded in glycosylated haemoglobin, ${ }^{16}$ emphasising that monitoring should not be seen $\bar{c}$ purely as a method for improving overall control.

At the first and simplest level of use spot checks of blood glucose allow detection and correction of hypoglycaemia $\underset{\infty}{\infty}$ before, for example, driving, exercising, or sleeping; such o tests are especially useful for patients who experience few warning signs of hypoglycaemia. Such selective testing, even infrequently, may result in a valuable boost to self confidence $\vec{N}$ but would not be expected to improve objective indicators of control. In young children, in whom frequent finger pricks may not be possible, occasional tests can be reassuring for $\vec{\sigma}$ both parent and child. ${ }^{17}$

At a second level regular testing and recording may be used to build up a profile of blood glucose concentrations to $\vec{\otimes}$ help establish the optimum insulin dose and also improve the patient's understanding of the factors that influence the blood 8 glucose. At a third level, with frequent daily tests insulin dosages may be altered frequently to correct short term swings in blood glucose concentrations. When testing is combined with continuous subcutaneous insulin infusion or multiple $\stackrel{D}{2}$ daily injections near normoglycaemia can be achieved-but $\overrightarrow{\mathrm{o}}$ probably only if the blood glucose concentration is tested four times a day with appropriate adjustment of the doses of insulin. ${ }^{18}$ Some flexibility of the carbohydrate intake can be safely allowed in these patients if they have a thorough knowledge of carbohydrate food values.

Self monitoring of blood glucose concentrations in noninsulin dependent diabetes has received less attention, but if normoglycaemia is desirable, in younger patients at least, urine $\bar{\xi}$ testing will be insufficiently sensitive. ${ }^{19}$ Fasting and mid o morning glucose concentrations correlate well with mean values over 24 hours, ${ }^{20}$ and occasional tests at a standard time would enable patients to monitor their own treatment and might promote dietary compliance.

Clearly the use made by patients of self monitoring techniques will vary, as will their responses to the barrage of new information confronting them. Those experiencing problems with control may welcome the opportunity for $\bar{D}$

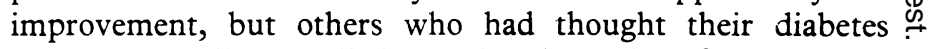
reasonably well controlled may be alarmed to find that this 0 is not the case. Some may become frustrated at their inability to control rapid swings in blood glucose. Patients are usually reluctant at first to change their insulin dosage without $\stackrel{\mathbb{D}}{\mathscr{D}}$ consultation with their doctor, and they need frequent 2 encouragement and supervision until they gain confidence. The doctor and his patient may have different interpretations of good control, one looking for normoglycaemia and the other for freedom from hypoglycaemia. 